\title{
Yoga in Health Care
}

\section{Ananda Balayogi Bhavanani *}

ABSTRACT: We are today faced with numerous debilitating chronic illnesses related to aging, environment, and hedonistic lifestyle, such as cancer, diabetes, osteoporosis, and cardiovascular diseases as well as many incurable diseases such as AIDS. Modern medical advancements provide the rationale for the integration of various traditional healing techniques including Yoga to promote healing, health, and longevity. It is imperative that advances in medicine include the wholistic approach of Yoga to face the current challenges in health care. The antiquity of Yoga must be united with the innovations of modern medicine to improve quality of life throughout the world. While modern medicine has a lot to offer humankind in its treatment and management of acute illness, accidents and communicable diseases, Yoga has a lot to offer in terms of preventive, promotive and rehabilitative methods in addition to many management methods to tackle modern illnesses. While modern science looks outward for the cause of all ills, the Yogi searches the depth of his own self. This two way search can lead us to many answers for the troubles that plague modern man. It is suggested that a two way integration of the experimentally tempered modern science with the experientially modelled science of Yoga can lead us to many answers for challenges plaguing modern humankind such as debilitating chronic illnesses related to aging, environment, and hedonistic lifestyle. Modern medical advancements provide the rationale for the integration of various traditional healing techniques including Yoga to promote healing, health, and longevity. It is imperative that advances in medicine include the wholistic approach of Yoga to face the current challenges in health care. The antiquity of Yoga must be united with the innovations of modern medicine to improve quality of life throughout the world.

\section{INTRODUCTION:}

Yoga is the original mind-body medicine that has enabled individuals to attain and maintain sukha sthanam, a dynamic sense of physical, mental and spiritual well being. Bhagavad-Gita defines Yoga as samatvam meaning thereby that Yoga is equanimity at all levels, a state wherein physical homeostasis and mental equanimity occur in a balanced and healthy harmony. Yogamaharishi Dr Swami Gitananda Giri Guru Maharaj, the visionary founder of Ananda Ashram at the International Centre for Yoga Education and Research (ICYER) in Pondicherry and one of the foremost authorities on Yoga in the past century, has explained the concept of Yoga Chikitsa (Yoga as a therapy) in the following lucid manner. "Yoga Chikitsa is virtually as old as Yoga itself, indeed, the 'return of mind that feels separated from the Universe in which it exists' represents the first Yoga therapy. Yoga Chikitsa could be termed as "man's first attempt at unitive understanding of mind-emotions-physical distress and is the oldest wholistic concept and therapy in the world."

To achieve this Yogic integration at all levels of our being, it is essential that we take into consideration the all encompassing multi dimensional aspects of Yoga that include the following: a healthy life nourishing diet, a healthy and natural environment, a wholistic lifestyle, adequate bodywork through Asanas, Mudras and Kriyas, invigorating breath work through the use of Pranayama and the production of a healthy thought process through the higher practices of Jnana Yoga and Raja Yoga.

\section{PSYCHOSOMATIC DISORDERS:}

From the Yogic viewpoint of disease it can be seen that psychosomatic, stress related disorders appear to progress through four distinct phases. These can be understood as follows:

1. Psychic Phase: This phase is marked by mild but persistent psychological and behavioural symptoms of stress like irritability, disturbed sleep and other minor symptoms. This phase can be correlated with vijnanamaya and manomaya koshas. Yoga as a mind body therapy is very effective in this phase.

2. Psychosomatic Phase: If the stress continues there is an increase in symptoms, along with the appearance of generalized physiological symptoms such as occasional hypertension and tremors. This phase can be correlated with manomaya and pranamaya koshas. Yoga as a mind body therapy is very effective in this phase.

3. Somatic Phase: This phase is marked by disturbed function of organs, particularly the target, or involved organ.

\footnotetext{
* Yogacharya Dr.Ananda Balayogi Bhavanani , Hon Advisor CYTER, MGMCRI
} 
At this stage one begins to identify the diseased state. This phase can be correlated with pranamaya and annamaya koshas. Yoga as a therapy is less effective in this phase and may need to be used in conjunction with other methods of treatment.

4. Organic Phase: This phase is marked by full manifestation of the diseased state, with pathological changes such as an ulcerated stomach or chronic hypertension, becoming manifest in their totality with their resultant complications. This phase can be correlated with the annamaya kosha as the disease has become fixed in the physical body. Yoga as a therapy has a palliative and quality of life improving effect in this phase. It also has positive emotional and psychological effects even in terminal and end of life situations.

\section{POTENTIALITIES OF YOGA:}

Extensive research on Yoga being done all over the world has shown promise with regard to various disorders and diseases that seem to be amiable to Yoga therapy (www.iayt.org, www.icyer.com, www.svyasa.org ). These include psychosomatic, stress disorders such as bronchial asthma, diabetes mellitus, hypertension, irritable bowel syndrome, gastro intestinal ulcer diseases, atherosclerosis, seizure disorder and headache. It also includes physical disorders such as heart disease, lung disease, and mental retardation. Psychiatric disorders such as anxiety disorders, obsessive-compulsive disorder, depression and substance abuse can also be managed along with other therapies. Musculoskeletal disorders such as lumbago, spondylosis, sciatica and carpel tunnel syndrome can be tackled effectively with Yoga practices that offer a lot of hope in metabolic disorders such as thyroid and other endocrine disorders, immune disorders, obesity and the modern metabolic syndrome.

According to Dr B Ramamurthy, eminent neurosurgeon, Yoga practice re-orients the functional hierarchy of the entire nervous system. He has noted that Yoga not only benefits the nervous system but also the cardiovascular, respiratory, digestive, endocrine systems in addition to bringing about general biochemistry changes in the yoga practitioners. Dr. Dean Ornish, the eminent American doctor who has shown that Yogic lifestyle can reverse heart isease says, "Yoga is a system of perfect tools for achieving union as well as healing". Dr Swami Gitananda Giri says, "Yoga is scientific and many of it practices can be measured by existing scientific methods. As a science of mind it offers a safe method of concentration and meditation educing a practical application of the power of the human mind. Its entire process is centered in awareness that is why I call it the science of awareness."

It is well established that stress weakens our immune system. Scientific research in recent times has showed that the physiological, psychological and biochemical effects of Yoga are of an anti-stress nature. Mechanisms postulated included the restoration of autonomic balance as well as an improvement in restorative, regenerative and rehabilitative capacities of the individual. A healthy inner sense of wellbeing produced by a life of Yoga percolates down through the different levels of our existence from the higher to the lower producing health and wellbeing of a holistic nature. Streeter

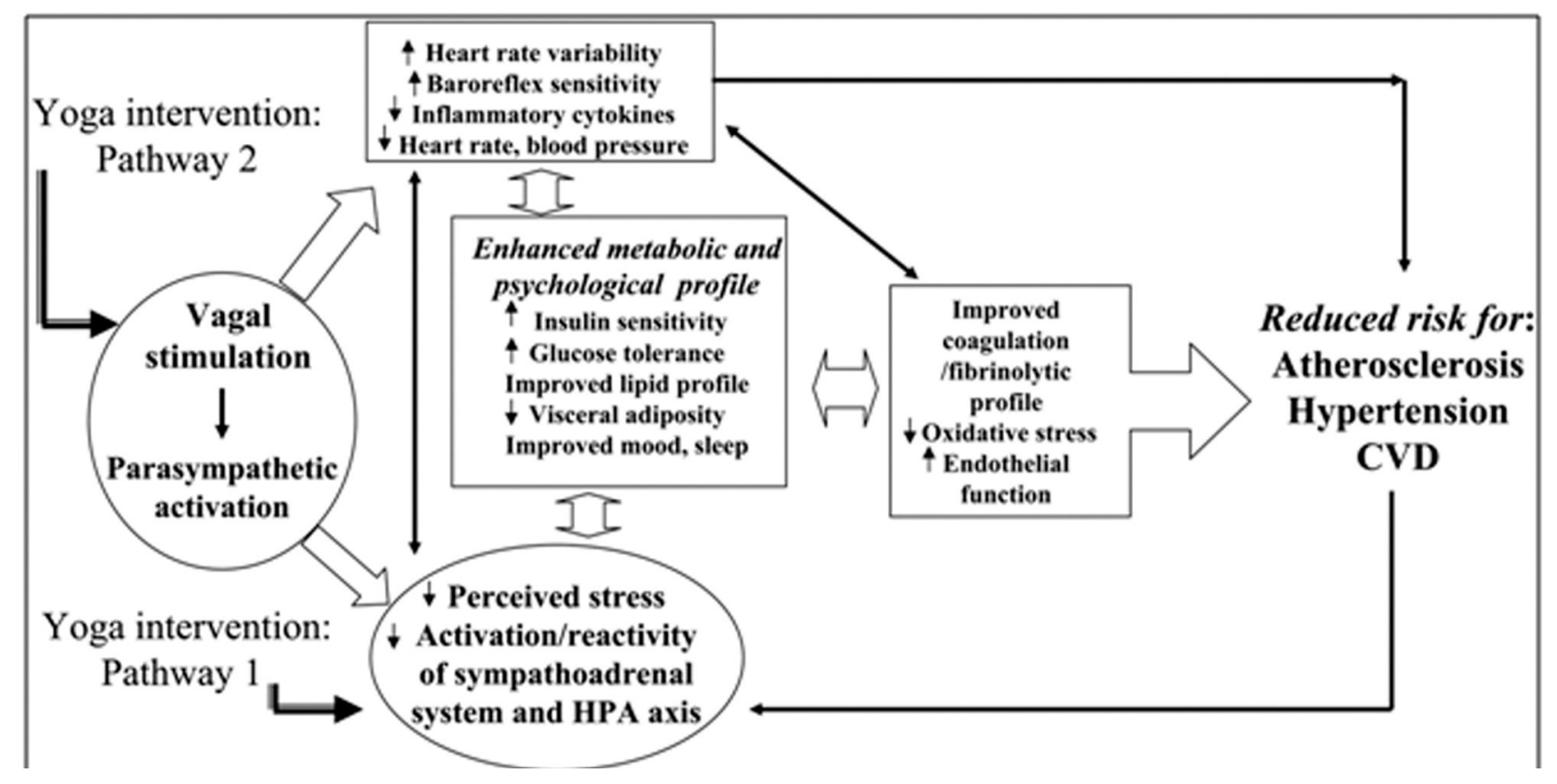


et al (Med Hypotheses 2012;78: 571-9) recently proposed a theory to explain the benefits of Yoga practices in diverse, frequently comorbid medical conditions based on the concept that Yoga practices reduce allostatic load in stress response systems such that optimal homeostasis is restored. According to the theory proposed by Streeter and colleagues, the decreased parasympathetic nervous system and GABAergic activity that underlies stress-related disorders can be corrected by Yoga practices resulting in amelioration of disease symptoms. HRV testing has a great role to play in our understanding intrinsic mechanisms behind such potential effects of Yoga.

Innes et al had earlier (J Am Board Fam Pract 2005; 18: 491-519) also postulated two interconnected pathways (given below) by which Yoga reduces the risk of cardiovascular diseases through parasympathetic (vagal) activation coupled with reductions in per4ceived stress and decreased reactivity of sympathoadrenal system and HPA axis. Innes and Vincent (eCAM 2007; 4: 469-86) also postulated similar mechanisms to be operating in reducing risk for Type 2 Diabetes mellitus (DM 2) and for complications related to DM 2.

\section{PSYCHOSOMATIC MECHANISMS OF YOGA:}

Yoga understands the influence of the mind on the body as well as that of the body on the mind. This is the principle of adhi-vyadhi elucidated in the Yoga Vasishta more than 5000 years ago! It is interesting that modern medicine has only realised this connection in the last hundred years whereas Yogic of India were teaching and practising it for thousands of years. No wonder Yoga may be considered as the original mind-body medicine.

We are what we think, yet we also start to think that which we do. Yogic concepts and techniques enable the development of right attitudes towards life and enable us to correct the numerous internal and external imbalances we suffer due to our wrong lifestyle/ genetic potential. Yoga enables us to take responsibility for our own health and happiness and as Swami Gitananda Giri would say, "If you want to be healthy do healthy things, if you want to be happy do happy things".

The following are just a few of the mechanisms through which Yoga can be said to work as an integrated mind-body medicine:

1. Cleanses the accumulated toxins through various shuddi kriyas and generates a sense of relaxed lightness through jathis and vyayama type activities. Free flow in all bodily passages prevents the many infections that may occur when pathogens stagnate therein.

2. Adoption of a Yogic lifestyle with proper nourishing diet, creates positive antioxidant enhancement thus neutralizing free radicals while enabling a rejuvenative storehouse of nutrients packed with life energy to work on anabolic, reparative and healing processes .

3. Steadies the entire body through different physical postures held in a steady and comfortable manner without strain. Physical balance and a sense of ease with oneself enhance mental / emotional balance and enable all physiological processes to occur in a healthy manner.

4. Improves control over autonomic respiratory mechanisms though breathing patterns that generate energy and enhance emotional stability. The mind and emotions are related to our breathing pattern and rate and hence the slowing down of the breathing process influences autonomic functioning, metabolic processes as well as emotional responses.

5. Integrates body movements with the breath thus creating psychosomatic harmony. In Yoga the physical body is related to annamaya kosha (our anatomical existence) and the mind to manomaya kosha (our psychological existence). As the pranayama kosha (our physiological existence sustained by the energy of the breath) lies in between them, the breath is the key to psychosomatic harmony.

6. Focuses the mind positively on activities being done, thus enhancing energy flow and resultant healthy circulation to the different body parts and internal organs. Where the mind goes, there the prana flows!

7. Creates a calm internal environment through contemplative practices that in turn enable normalization of homeostatic mechanisms. Yoga is all about balance or samatvam at all levels of being. Mental balance produces physical balance and vice versa too.

8. Relaxes the body-emotion-mind complex through physical and mental techniques that enhance our pain threshold and coping ability in responding to external and internal stressors. This enhances the quality of life as seen in so many terminal cases where other therapies are not able to offer any solace.

9. Enhances self confidence and internal healing capacities through the cultivation of right attitudes towards life and moral-ethical living through yama-niyama and various Yogic psychological principles. Faith, self confidence and 
inner strength are most essential if at all we wish for healing, repair, rejuvenation and re-invigoration.

10. Yoga works towards restoration of normalcy in all systems of the human body with special emphasis on the psycho-neuro-immuno-endocrine axis. In addition to its preventive and restorative capabilities, Yoga also aims at promoting positive health that will help us to tide over health challenges that occur during our lifetime. This concept of positive health is one of Yoga's unique contributions to modern healthcare as Yoga has both a preventive as well as promotive role in the healthcare of our masses. It is also inexpensive and can be used in tandem with other systems of medicine in an integrated manner to benefit patients.

\section{INTEGRATING YOGA AND MODERN MEDICINE:}

At first glance, allopathic medicine and Yoga may seem to be totally incompatible and in some ways even antagonistic to each other. Practitioners of either system are often found at loggerheads with one another in typical modern oneupmanship. However it is my humble endeavor as a student of both these life giving, life changing and life saving sciences, to find the similarities that exist between them and build a bridge between these two great sciences of today's world. It would of course be much easier to build a bridge between Yoga and Ayurveda as both share many similarities of concepts such as the Trigunas, Tridoshas, Chakras and Nadis. They also understand that a healthy balance between body, mind and soul leads to total health. Diet and behavior are given importance in both systems and the ultimate goal of both is the attainment of Moksha. Though modern medicine may not share all of these concepts with Yoga, it is to be seen that there are a great many 'meeting points' for the construction of a healthy bridge between them. Both modern medicine and Yoga understand the need for total health and even the Word Health Organization has recently added a new dimension to the modern understanding of health by including spiritual health in its definition of the "state of health'. Spiritual health is an important element of Yoga and now that even the WHO has come around to understanding this point of view, there is hope for a true unification of these two systems. Modern medicine has the ultimate aim and goal of producing a state of optimum physical and mental health thus ultimately leadings to the optimum well being of the individual. Yoga also aims at the attainment of mental and physical well being though the methodology does differ. While modern medicine has a lot to offer humankind in its treatment and management of acute illness, accidents and communicable diseases, Yoga has a lot to offer in terms of preventive, promotive and rehabilitative methods in addition to many management methods to tackle modern illnesses. While modern science looks outward for the cause of all ills, the Yogi searches the depth of his own self. This two way search can lead us to many answers for the troubles that plague modern man.

The potential and manifest integration of Yoga and modern medical science can be discussed under different sub headings as follows:

\section{PROMOTION OF POSITIVE HEALTH:}

Yoga is an excellent tool of promotive health that can enrich modern medicine. The practice of Yoga leads to the efficient functioning of the body with homeostasis through improved functioning of the psycho-immuno-neuro-endocrine system. A balanced equilibrium between the sympathetic and parasympathetic wings of the autonomic nervous system leads to a dynamic state of health. Yogi Swatmarama in the Hathayoga Pradipika, one of the classical Yoga texts gives us the assurance, "One who tirelessly practises Yoga attains success irrespective of whether they are young, old decrepit, diseased or weak". He gives us the guarantee that Yoga improves health of all alike and wards off disease, provided we properly abide by the proper rules and regulations (yuvaa vrddho ativriddho vaa vyaadhito durbalo pi vaa abhyaasaat siddhimaapnoti sarvayogeshvatandritah-Hathayoga Pradipika I:64). The World Health Organization (WHO) defines health as a state of complete physical, mental, and social well being and not merely absence of disease or infirmity. WHO has also in recent times suggested a fourth dimension of spiritual health but has fallen short of defining it without confusing it with religion. From a Yogic perspective it is heartening that the WHO definition gives importance to 'well being' that is a vital aspect of 'being' healthy as well as 'feeling' healthy. There is no use in a doctor telling patients that all their investigations are 'normal' when the patients themselves are not feeling 'well'. This qualitative aspect of health is something that Yoga and Indian systems of medicine have considered important for thousands of years. The definition of asana given in the Yoga Sutra as sthira sukham implies this state of steady well being at all levels of existence (sthira sukham asanam- Yoga Darshan II:46). Patanjali also tells us that through the practice of asana we can attain a state that is beyond dualities leading to a calm and serene state of well being (tato dvandva anabhighata- Yoga Darshan II: 48). Yoga aims at enabling the individual to attain and maintain a dynamic sukha sthanam that may be defined as a dynamic sense of physical, mental and spiritual well being. The Bhagavad Gita defines Yoga as samatvam meaning thereby that Yoga is equanimity at all levels. (yogasthah kurukarmani sangam tyaktva dhananjaya siddiyasidhyoh samobutva samatvam yoga uchyate - Bhagavad Gita II: 48) This may be also understood as a perfect state of health wherein physical 
homeostasis and mental equanimity occur in a balanced and healthy harmony.

One of the main lacunae of the WHO definition lies in the use of the term 'state' that implies health is something to be achieved 'once and for all' with no need for care about it thereafter! It is definitely not so. We need to keep working on our health with great vigour and dynamic enthusiasm for the entire span of our life. If health is to be understood as a 'state', then it must be understood as a dynamic state that varies from day-to-day and often from minute-to-minute! It is often actually more challenging to maintain this dynamic state of health than to even attain it in the first place. Ask any World No.1 sports champion and they will testify to this inherent truth that applies to sports as well as to life itself.

\section{MANAGEMENT OF DISEASES AND DISORDERS:}

Yoga doesn't negate the use of drugs and other methods of modern medicine. Maharishi Patanjali in his Avatar as Charaka didn't shy away from the need to use medicinal herbs as well as surgical methods when necessary for the benefit of the patient. The system of Ayurveda is more in tune with the Yogic views of healing in this regard but definitely the modern antibiotic treatment of infectious diseases as well as the emergency medical and trauma management techniques of modern medicine must be understood to be life-savers in times of need. No Yoga therapist in his or her right mind should try to treat an acute myocardial infarction or an unconscious accident victim by Yoga alone. A symbiotic relationship between the techniques of modern medicine and Yoga can help the patient more than a dogmatic refusal to see the 'other side'. Yoga has a lot to offer in terms of psychosomatic disorders and in stress related disorders such as diabetes, asthma, irritable bowel syndrome, epilepsy, hypertension, back pain and other functional disorders. Yoga can help reduce and in some cases eliminate drug dosage and dependence in patients suffering from diabetes mellitus, hypertension, epilepsy, anxiety, bronchial asthma, constipation, dyspepsia, insomnia, arthritis, sinusitis and dermatological disorders.

To quote Dr Steven F Brena, "Yoga is probably the most effective way to deal with various psychosomatic disabilities along the same, time-honored, lines of treatment that contemporary medicine has just rediscovered and tested. Asanas are probably the best tool to disrupt any learned patterns of wrong muscular efforts. Pranayama and Pratyahara are extremely efficient techniques to divert the individual's attention from the objects of the outer environment, to increase every person's energy potentials and 'interiorize' them, to achieve control of one's inner functioning. Moreover, in restoring human unity, the Yoga discipline is always increasing awareness and understanding of ourselves, adjusting our emotions, expanding our intellect, and enabling us not only to function better in any given situation, but to perform as spiritual beings with universal values." Yoga therapists must work in tandem with medical doctors when they are treating patients who have been on allopathic treatment. There are many instances where the patient stops medical treatment thinking that it no more necessary as they have started Yoga. This leads to many catastrophes that could be easily avoided by tandem consultations with a medical specialist. Similarly many modern doctors tend to tell the patient to take up Yoga or relaxation and forget to mention to the therapist what they actually want the patients to do. Most allopathic medications need to be tapered off in a progressive manner rather than being stopped suddenly. We often find this mistake in regard to corticosteroids as well as cardiac medications where sudden stoppage can be harmful. We must remember Plato's words when he said, “The treatment of the part shouldn't be attempted without a treatment of the entirety," meaning that the treatment of the body without treating the mind and soul would be a useless waste of time.

\section{REHABILITATION:}

Yoga as a physical therapy has a lot to offer patients of physical and mental handicaps. Many of the practices of physiotherapy and other physical therapies have a lot in common with Yoga practices. Mentally challenged individuals can benefit by an improvement in their IQ as well as in learning to relate to themselves and others better. As their physiological functions improve with Yoga, the combination of Yoga and physical therapies can benefit such patients as well as those with learning disabilities. Musculoskeletal problems can be treated by the combination to improve function as well as range of movement, strength and endurance abilities. Balance and dexterity can also be improved by the combination therapy. The use of Yoga can help those recovering from accidents and physical traumas to get back on their feet faster and with better functional ability. An example of this was Dr Swami Gitananda Giri who managed to get back on his feet and function normally after a debilitating stay in a full body cast for more than six months. Swamiji used to say, "Modern medicine kept me alive, but Yoga gave me back my life as otherwise I may have been a cripple for life". Yoga also has a lot to offer those suffering from drug and substance abuse in assisting them to get back to a normal life. Yoga helps develop their self-control and will power and also gives them a new philosophy of living. This is vital as otherwise they will lapse into their old negative habits. 


\section{HEALTHY DIET:}

This is a place that modern medicine and Yoga can help give a patient as well as normal person the proper wholistic values of a proper diet. Modern research shows us the benefits of the 'break-down' study of foods on the basis of their physical and chemical properties. This is important for the person to know how much of each constituent of food is to be taken in the proper quantity. Yoga can help a person to learn the right attitude towards food as well as understand concepts based on the Trigunas and Tridoshas for better health. Yoga teaches us that the cause of most disease is through under (Ajjeranatvam), over (Atijeeranatvam) or wrong (Kujeeranatvam) digestion. Yoga also teaches us about the approach to food, the types of food as well as the importance of timings and moderation in diet. A combination of the modern aspects of diet with a dose of Yogic thought can help us eat not only the right things but also in the right way and at the right time thus ensuing our good health and longevity. Yoga emphasizes the importance of not only eating the right type of food but also the right amount and with the right attitude. Importance of not eating alone, as well as preparation and serving of food with love are brought out in the Yogic scheme of right living. Guna (inherent nature) of food is taken into consideration to attain and maintain good health. Modern dietary science of diet can learn a lot from this ancient concept of classification of food according to inherent nature as it is a totally neglected aspect of modern diet. We are what we eat! The great Tamil poet-saint Tiruvalluvar offers sane advice on right eating when he says, "He who eats after the previous meal has been digested, needs not any medicine." (marunthuena vaendaavaam yaakkaikku arundiyathu atrathu poatri unnin-Tirukkural 942). He also says that life in the body becomes a pleasure if we eat food to digestive measure (attraal alavuarinthu unga aghduudambu pettraan nedithu uikkum aaruTirukkural 943). He also invokes the Yogic concept of Mitahara by advising that "eating medium quantity of agreeable foods produces health and wellbeing” (maarupaaduillaatha undi marutthuunnin oorupaadu illai uyirkku -Tirukkural 943).

\section{PSYCHOSOMATIC RELAXATION:}

Most medical doctors understand that it is important to relax in order to get better. The problem is that, though the doctor tells the patient to relax, they don't tell them how to do so and maybe in fact they don't know the answer themselves in the first place. Hatha Yoga and Jnana Yoga Relaxation practices help relax the body, emotions and mind. Relaxation is a key element of any Yoga therapy regimen and must not be forgotten at any cost. Shavasana has been reported to help a lot in hypertensive patients and practices such as Savitri Pranayama, Chandra Pranayama, Kaya Kriya, Yoga Nidra, Anuloma Viloma Prakriyas and Marmanasthanam Kriya are also available to the person requiring this state of complete relaxation. It is important to remember that relaxation on its own is less effective than relaxation that follows active physical exertion.

\section{COPING SKILLS:}

Yoga has a lot to offer those who unable to cope with death and dying as well as those suffering from incurable diseases. The Yoga philosophy of living sees death as an inevitable aspect of life that cannot be wished away. Swami Gitananda Giri used to tell us that the whole of life is, but a preparation for the moment of death, so that we can leave the body in the right way. Those who are taking care of the dying as well as those taking care of patients of incurable diseases and major disabilities are under an extreme amount of stress and Yoga practice as well as its philosophy helps them gain the inner strength necessary to do their duty. Yoga can help break the vicious spiral of pain-drug dosage-pain and by doing so help reduce the drug dosage in patients suffering chronic pain. It has been reported that Yoga helps improve the quality of life in patients suffering from cancer and also helps them cope better with the effects of treatment. It relaxes them and helps them sleep better. As someone rightly said, "Yoga may not be able to always cure but it can surely help us to endure".

\section{REDUCING EXPENDITURE:}

Modern medicine is often criticized for the cost involved in its methods of treatment. Yoga offers an inexpensive method of health that can be added to the medical armory when required. Yoga only requires the patient's own effort and really doesn't need any paraphernalia. Of course the modern Yoga industry would rather have us believe that we need tons of Yoga equipment to start Yoga, but they are awfully of the mark in this case. Reduction in drug dosage and avoidance of unnecessary surgeries in many cases can also help reduce the spiraling cost of Medicare.

\section{HEALTHY AGING:}

Aging is inevitable and Yoga can help us to age gracefully. Modern medicine tries to help retard aging and help 
people look better by costly surgical methods that are only an external covering over the underlying aging process. Healthy diet, regular exercise, avoidance of negative habits and cultivation of the positive habits and a healthy lifestyle can help us to age with dignity. Yoga can also help our 'silver citizens' retain their mental ability and prevent degenerative disorders such as Parkinson's disease, Alzheimer's and various other dementias. Physical accidents such as falls can be minimized and many an artificial hip, knee or shoulder replacement surgery can be avoided. My own revered fatherGuru Swami Gitananda Giri, Yogashri T Krishnamacharya, Sri Kannaiah Yogi, Swami Suddananda Bharathi, Sri Yogeshwarji, Sri Yogendraji, Sri pattabi Jois and Padma Bhushan BKS Iyengarji are but a few of the Yogis who have shown us that its is possible to grow old without losing any of the physical or mental faculties of youth.

\section{PSYCHOTHERAPY:}

In the field of psychotherapy and psychoanalysis we can find a lot of ancient Yogic concepts being reiterated time and again. Many modern psychotherapeutic concepts such as identification, projection, and transference are similar to concepts in Yoga psychology. Yoga psychology integrates diverse principles within a single body. CG Jung had a great interest in Yoga and the eastern thought and said, "Chakras represent a real effort to give a symbolic theory of the psyche”. His 'Centre of Personality' concept based on dream analysis is very similar to the Yogic concept of a central psychic or spiritual personality. He also correlated Chakras to the archetypes that abound in the collective unconscious. Yoga helps the psychotherapist in training self awareness, and in the self regulation of body, diet, breath, emotions, habit patterns, values, will unconscious pressures and drives. It also helps in relating to the archetypal processes and to a transient being. It offers an integrated method rather than one that is found in isolation in many different therapies. The theory of Kleshas is an excellent model for psychotherapy while emotional therapies of Yoga include Swadhyaya, Pranayama, Pratyahara, Dharana, Dhyana and Bhajans. Development of proper psychological attitudes is inculcated via the concepts of Vairagya, Chitta Prasadanam as well as Patanjali's advise on adopting the attitudes of Maitri, Karuna, Mudita and Upekshanam towards the happy, the suffering, the good and the evil minded persons. Yoga also has a lot to offer in terms of spiritual therapies such as Swadhyaya, Satsangha, Bhajans and Yogic counseling. It is also interesting to note that both Yoga and psychoanalysis share common ground in understanding that symptoms of the disease are often willed by the patients. While all psycho analysists must undergo psychoanalysis themselves, it is taught in Yoga that one must first undergo a deep Sadhana, before attempting to guide others on the path. However while psychoanalysis searches the unconscious, Yoga attempts to understand and explore the super conscious.

\section{LIFESTYLE CHANGES:}

Yoga helps patients take their health in their own hands. They learn to make an effort and change their life style for the better so that their health can improve. Life style modification is the buzzword in modern medical circles and Yoga can play a vital role in this regard. Yogic diet, Asanas, Pranayamas, Mudras, Kriyas and relaxation are an important aspect of lifestyle modification. To live a healthy life it is important to do healthy things and follow a healthy lifestyle. The modern world is facing a pandemic of lifestyle disorders that require changes to be made consciously by individuals themselves. Yoga places great importance on a proper and healthy lifestyle whose main components are Achar (healthy activities on a regular basis), Vichar (right thoughts and attitude towards life), Ahar (healthy, nourishing diet) and Vihar (proper recreational activities to relax body and mind)

\section{WOMEN'S HEALTH:}

Women are the chosen ones blessed with the responsibility of the future of our human race. Healthy mothers give birth to healthy babies and a healthy start has a great future ahead. Yoga has a lot to contribute in combination with modern medicine to the health status of womankind. Puberty and menopause become easier transitions with the help of Yoga and many eminent Yoginis have said that they were not even aware of a single menopausal symptom as they went through this difficult period in a woman's life. Similarly our young girls can vouch for the fact that their pubertal changes and menarche has been relatively smoother than their counterparts who don't practice Yoga. The benefits of Yoga in terms of family planning are also an important aspect that needs further study, as they can be an effective part of the contraceptive armory. The risk of side effects is negated and the entire control restored to the individuals themselves. The Oli Mudras as practiced in the Gitananda Yoga tradition have great potential in this regard and also the Swara Yoga theories of conception have a lot of exciting possibilities. Once conception occurs, Yoga helps the young mother to be, to prepare herself physically and mentally for the upcoming childbirth. Yoga helps open the joints of the pelvis and hip as well as strengthen the abdominal muscles for childbirth. Later, simple Pranayamas and relaxation techniques help the new mother relax and enjoy the new experience of her life. Post partum introduction of simple practices along with 
breathing, relaxation and a lot of crawling helps her come back to normal earlier and this can be used in all maternity hospitals along with allopathic management. Yoga practices can also help reduce the drug dosage in medical problems that often complicate a normal pregnancy such as diabetes, asthma and hypertension.

\section{RESEARCH:}

The positive benefits of Yoga research are of vital significance and an understanding of how the various practices work in different conditions and in normal situations are of great value for both the science of Yoga as well as for the world of medicine. Yoga therapists can benefit a lot by a scientific understanding of Yoga postures and other techniques. This will bring about a rational approach to Yoga therapy rather than a haphazard application of individualistic knowledge. Under the department of AYUSH, Morarji Desai National Institute of Yoga has created advanced centers for Yoga in JIPMER, NIMHANS, AIIMS and DIPAS to promote all aspects of Yoga in these premier medical institutions of India. Various private institutions are running in our country and doing their best to propagate Yoga-Vidya. Yoga therapy is being used both in conjunction with modern medicine or alternative systems of medicine as well as on its own in various centers. Various conditions such as diabetes, hypertension, arthritis, mental depression, bronchial asthma etc have been found to be relieved by Yoga Therapy and centers such as ICYER at Ananda Ashram, sVYASA, Kaivalyadhama, The Yoga Institute and Krishnamacharya Yoga Mandiram are doing a great deal of work in this field. Though there is a lot of research on Yoga being done by medical doctors these days but it is important to remember Swami Gitananda Giri's words when he said, "We must research Yoga and not the lack of Yoga". Many studies are badly constructed and manya-time we find that the Yoga practices performed by the patients have no real relation to Yoga at all. The higher aspects of Yoga are still not in the 'researchable' realm of modern science.

\section{NEED FOR COORDINATION:}

The need of the modern age is to have an integrated approach towards therapy and to utilize Yoga therapy in coordination and collaboration with other systems of medicine such as Allopathy, Ayurveda, Siddha and Naturopathy. Physiotherapy and Chiropractic practices may be used with the Yoga if needed. Advice on diet and lifestyle is very important irrespective of the mode of therapy that is employed for a particular patient.

\section{PRESENT SCENARIO:}

The therapeutic potential of yoga has been recognized world over and studies have shown its beneficial effects in numerous psychosomatic disorders like diabetes, hypertension, asthma, arthritis and other chronic diseases that are a great burden on our health care delivery system. The International Association of Yoga Therapists in the USA (www. iayt.org) is doing a lot of work to make Yoga Therapy acceptable to the medical community worldwide. They have given details of hundreds of research studies done all of over the world with regard to yoga as a novel and adjunct therapy to be used along with modern medicine.

In India Yoga Therapy is under Dept of AYUSH in Ministry of Health and Family Welfare and through its Morarji Desai National Institute of Yoga (www.yogamdniy.nic.in) five Advanced Centers for Yoga have been set up in our country. The Advanced Centre for Yoga Therapy, Education and Research (ACYTER), a collaborative venture between JIPMER and MDNIY is functioning since June 2008 and focusing primarily on the role of Yoga in the prevention and management of cardiovascular disorders and diabetes mellitus. More than 30,000 patients have benefited from the Yoga therapy consultations and practical sessions till date. The centre also aims to popularize the science of yoga among medical professionals (Yoga Vijnana 2008; 2: 71-78) and general public and has conducted workshops and awareness programmes to this effect.

Central Council for Research in Yoga and Naturopathy in the Ministry of Health and Family Welfare (www. ccryn.org) funds research studies in Yoga and ran a National Programme on Yoga and Naturopathy in 2010-2011. Yoga therapists have been appointed under the NRHM programmes in government hospitals all over the country and most major private medical hospitals have established Yoga and Healthy Living Centers.

Though there are many private hospitals hosting Healthy Lifestyle Centers for their patients, it is only in recent times that the Public Sector Hospitals have started such centers. AIIMS was one of the first centers to have such a unit (Indian J Physiol Pharmacol 2008; 52: 123-31) but today numerous units are functioning all over the country under the 
patronage of the Ministry of Health and Family Welfare, Government of India.

The Centre for Yoga Therapy, Education and Research (CYTER) is running at MGMC\&RI under the patronage of Sri Balaji Vidyapeeth and a scientifically sound Yoga therapy programme is running since 2010. Awareness programmes have been conducted for medical and paramedical personnel and more than 5000 patients have benefited till date and many studies under publication.

\section{A WORD OF CAUTION:}

A word of caution is also required. Though Yoga and Yoga therapy are very useful in bringing about a state of total health it is not a miracle cure for all problems. It needs a lot of discrimination on the part of both the therapist as well as the patient. It may not be useful in emergency conditions and there is a strong need to consult a qualified medical doctor where in doubt. Each patient is different and so the therapy has to be molded to suit the individual needs rather than relying on a specific therapy plan for patients suffering the same medical condition. A very true problem is that there is a different approach of the different schools of Yoga to the same condition. It is better to follow any one system that one is conversant with, rather than trying to mix systems in a "Yogic Cocktail'. One must also be vigilant as there is a strong presence of numerous quacks pretending to be Yoga therapists and this leads to a bad name for Yoga therapy as well as Yoga in general.

\section{CONCLUSION:}

The art and science of Yoga has infinite possibilities for providing answers to most health problems troubling modern humankind. However we often misunderstand this science and want it to be a miracle pill. A pill that we take only once, and want all the problems to vanish into thin air! Yoga is a wholistic science and must be learnt and practiced with a holistic view. The dedicated practice of Yoga as a way of life is no doubt a panacea for problems related to psychosomatic, stress related physical, emotional and mental disorders and helps us regain our birthright of health and happiness. It is only when we are healthy and happy that we can fulfill our destiny. With the adoption of a proper attitude and lifestyle through the Yogic way of life, we can rise above our own circumstances and our life can blossom as a time of variety, creativity, and fulfillment. Yoga helps us regain the ease we had lost through dis-ease (as implied by sthira sukham asanam-PYS). It also produces mental equanimity (samatvam yoga uchyate-BG) where the opposites cease to affect (tato dwandwa anabhigatha-PYS). This enables us to move from a state of illness and disease to one of health and wellbeing that ultimate allows us to move from the lower animal nature to the higher human nature and finally the highest Divine Nature that is our birthright.

\section{REFERENCES AND RECOMMENDED READING:}

1.Ajaya Swami. Psychotherapy East and West. Himalayan institute, Pennsylvania, USA 1983.

2.Anand BK. Yoga and Medical Sciences. Souvenir: Seminar on Yoga, science and man. Central council for re search in Indian Medicine and Homeopathy. New Delhi. 1976.

3.Anantharaman TR. Ancient Yoga and Modern Science. Mushiram Manoharlal Publishers Pvt Ltd, New Delhi. 1996

4.Anantharaman TR. Yoga as Science. Souvenir: Seminar on Yoga, science and man. Central council for research in Indian Medicine and Homeopathy. New Delhi. 1976.

5.Back issues of International Journal of Yoga Therapy. Journal of the International Association of Yoga Therapists, USA. www.iayt.org

6.Back issues of Yoga Life, Monthly Journal of ICYER at Ananda Ashram, Pondicherry. www.icyer.com

7.Back issues of Yoga Mimamsa. Journal of Kaivalyadhama, Lonavla, Maharashtra.

8.Bhatt GP. The Forceful Yoga (being the translation of the Hathayoga Pradipika, Gheranda Samhita and Siva Samhita). Translated into English by Pancham Sinh, Rai Bahadur Srisa Chandra Vasu. Mothilal Banarsidas Publishers Pvt Ltd, Delhi. 2004.

9.Bhavanani AB, Ramanathan M, Harichandrakumar K T. Immediate effect of mukha bhastrika (a bellows type pranayama) on reaction time in mentally challenged adolescents. Indian J Physiol Pharmacol 2012; 56 : 174-180

10.Bhavanani AB. Concepts of Health in Dravidian Yogic Treatises. Open Access Scientific Reports 2012; 1: 123. doi:10.4172/scientificreports.123

11.Bhavanani AB. Don't Put Yoga in a Small Box: The Challenges of Scientifically Studying Yoga. International Journal Of Yoga Therapy $2011 ; 21 ; 21$.

12.Bhavanani AB. Understanding the Science of Yoga. SENSE, 2011, Vol. 1 (1), 334-344

13.Bhavanani AB. Yoga as a therapy: A perspective. Yoga Mimamsa Vol. XLII (January 2011) No. 4 pp 235-241.

14.Bhavanani AB. A primer of Yoga theory. Dhivyananda Creations. Puducherry-13. (2008)

15.Bhavanani AB. A Yogic Approach to Stress. Dhivyananda Creations, Iyyanar Nagar, Pondicherry. (2ndedition) 2008. 
16.Bhavanani AB. Yoga for health and healing. Dhivyananda Creations. Puducherry-13. (2008)

17.Bhavanani AB. Yoga Therapy Notes. Dhivyananda Creations, Iyyanar Nagar, Pondicherry. 2007

18.Brena Steven F. Yoga and medicine. Penguin Books Inc. USA. 1972.

19.Carlson LE et al. Mindfulness-based stress reduction in relation to quality of life, mood, symptoms of stress, and immune parameters in breast and prostate cancer outpatients. Psychosom Med. 2003 Jul-Aug; 65(4): 571-81.

20.Chidbhavananda Swami. The Bhagavad Gita. Ramakrishna Tapovanam, Trichy, 1984

21.Datey KK, Deshmukh SN, Dalvi CP, Vinekar SL. "Shavasana": A yogic exercise in the management of hypertension'. Angiology 1969 ; 20: 325-333.

22.Feuerstein Georg. The Shambala Guide to Yoga. Shambala Publications Inc, Boston, Massachusetts, and USA.1996.

23.Gitananda Giri Swami and Meenakshi Devi Bhavanani (Ed). Bridging the gap between Yoga and science. Souvenir of the international conference on biomedical, literary and practical research in Yoga. ICYER, Pondicherry, India. July 25-28, 1991.

24.Gitananda Giri Swami. Yoga the art and science of awareness. Souvenir 1996; 4thInternational Yoga Festival, Govt of Pondicherry.

25.Gitananda Giri Swami. Yoga: Step-by-Step, Satya Press, Pondicherry, 1976.

26.Go VL and Champaneria MC. The new world of medicine: prospecting for health. Nippon Naika Gakkai Zasshi. 2002 Sep 20; 91 Suppl: 159-63.

27.Innes KE, Vincent HK. The Influence of Yoga-based programs on risk profiles in adults with type 2 diabetes mellitus: A systematic review. eCAM 2007; 4: 469-86.

28.Innes KE, Bourguignon C, Taylor AG. Risk indices associated with the insulin resistance syndrome, and possible protection with Yoga: a systematic review. J Am Board Fam Pract 2005; 18: 491-519

29.Khalsa SBS. Yoga as a therapeutic intervention: a bibliometric analysis of published research studies. Indian J Physiol Pharmacol 2004; 48: 269-85.

30.Madanmohan, Rai UC, Balavittal V, Thombre DP, Swami Gitananda. Cardiorespiratory changes during savitri pranayama and shavasan. The Yoga Review 1983; 3: 25-34.

31.Madanmohan. Introducing Yoga to medical students: the JIPMER experience. Yoga Vijnana 2008; 2: 71-78.

32.Nagarathna R and Nagendra HR. Integrated approach of Yoga therapy for positive health. Swami Vivekananda Yoga Prakashana, Bangalore, India. 2001.

33. Ramamurthi B. Uphill all the way. Guardian press, Chennai. 2000.

34.Ramanathan Meena. Thiruvalluvar on Yogic Concepts. Aarogya Yogalayam, Venkateswara Nagar, Saram, Pondicherry-13.2007

35. Selvamurthy W, Sridharan K, Ray US, Tiwary RS, Hegde KS, Radhakrishan U et al. A new physical approach to control essential hypertension. Indian J Physiol Pharmacol 1998; 42: 205-13.

36.Sharma R, Gupta N, Bijlani RL. Effect of Yoga based lifestyle intervention on subjective well-being. Indian J Physiol Pharmacol 2008; 52: 123-31.

37. Streeter CC, Jensen JE, Perlmutter RM, Cabral HJ, Tian H, Terhune DB et al. Yoga asana sessions increase brain GABA levels: a pilot study. J Altern Complement Med 2007; 13: 419-26.

38. Swami Satyananda Saraswathi. Four Chapters on Freedom. Bihar School of Yoga, Munger, India. 1999 39.Vijayalakshmi P, danmohan, Bhavanani AB, Patil A, Kumar Babu P. Modulation of stress induced by iso metric handgrip test in hypertensive patients following yogic relaxation training. Indian J Physiol Pharmacol 2004; 48: 59-64

40.Yoga the Science of Holistic Living. Vivekananda Kendra Patrika. Vol. 17- 2. 1988. 